\title{
Work, Violence and Health Safety at Work, In Vlora Regional Hospital over the Year
}

\section{Selfo D*}

Department of Nursing, Faculty of Public Health, University Ismail Qemali of Vlore, Albania

*Corresponding author: Selfo D, Department of Nursing, Faculty of Public Health, University Ismail Qemali of Vlore, Albania, Email: denadaselfo@yahoo.com

\section{Research Article}

Volume 4 Issue 3

Received Date: May 20, 2020

Published Date: June 26, 2020

DOI: $10.23880 /$ nhij-16000223

\section{Abstract}

Introduction: Health is a state of complete physical, mental and social and not merely the absence of disease or physical strength without the body. Work and health are closely related to each other. There is the fact that work can damage health. Hospital employees, especially nursing staff, are exposed to a number of risks, such as physical agents, chemicals, body postures, violence. The effects of violence can be physical or psychological.

The Purpose of the Study: to assess the level of violence in Vlora Regional Hospital, as well as the knowledge that nurses have about the job, their health and safety.

Methodology: This is a descriptive analytical study conducted in Vlora Regional Hospital in the period November 2018December 2019. Data collection is using a self- administered questionnaire was completed by the two departments nurses, nurse of surgery department and urgency.

Results: Noted that in the emergency ward nurses are more likely to be part of violent physical acts. Both pavilions have a high rate of verbal violence in the nursing work. Verbal violence is higher than physical violence. Nurses in both pavilions claim to be informed that procedures exist to denounce violence.

Discussion: Acts of violence have been increasing month by month. Comparing to 2017-2018 this violence has been increasing. Most nurses in both wards claim to be aware of the fact that there are procedures to report violence.

Keywords: Workplace; Nurses; Violence; Nurse-patient relationships; Injuries; Safety; Health

\section{Introduction}

According to the World Health Organization "Health is the state of complete physical, mental and social well-being and not merely the absence of disease or physical weakness of the organism" (Andrija Stampar, first president of the General Assembly of the World Health Organization, 1946).

The link between work and health Work and health are closely linked, and health can be affected by both positive and negative health.
From a positive point of view - we develop our physical and intellectual abilities. From a negative point of view - he uses the professional skills of people, thus not allowing the development of their skills.

The workplace can affect health in many ways. Work can be detrimental to health, and many studies have focused on this aspect [1]. The risks are the first to be considered when it comes to occupational health. There is already clear evidence that the workplace is directly linked to a significant number of fatal injuries or not. 
The overall work environment and its effects on health are the most neglected aspect in the relationship between health and work.

Hospital staff, especially nursing staff, is exposed to a range of risks, such as:

$>$ exposure to infectious agents,

$>$ unsuitable postures,

$>$ lifting weights during manipulations with the patient,

$>$ numerous displacements,

$>$ exposure to irritating, allergic and/or mutagenic chemicals and to ionizing radiation, known to cause health damage to employees

$>$ Another risk is violence against health personnel

\section{What is Violence?}

The National Institute for Safety and Health defines violence in the workplace as a violent act involving physical assault, intimidation, insulting language or even murder directed at persons in office [2].

\section{Violence Includes}

Threats, Physical Aggression. The effects and consequences of violence are

\section{Physical effects}

- Severe injuries

- Temporary or permanent physical disability

- Psychological trauma

- Death.

\section{Psychological effects}

- Fear of returning to work disappointment

- Lack of trust in hospital administration and coping with colleagues.

- Low job satisfaction.

- Increased stress level.

- Changes in relationships with colleagues and family.

- Feelings of helplessness, guilt, helplessness

\section{In the US}

Nurses are among the most attacked workers in the American workforce. The injured are mostly female nurses aged 26 to 64, more than 10 years of experience who have suffered various physical and verbal attacks [3]. Mostly from white male patients, 26 years to 35 years, who were confused or influenced by alcohol or drugs. In the U.S. emergency departments about $25 \%$ of respondents reported experiencing physical violence more than 20 times in the last 3 years, and nearly $20 \%$ reported experiencing verbal abuse more than 200 times during the same period.
In Hong Kong Nurses reported abuse of any kind - verbal abuse, 73\%; harassment, 45\%; physical abuse, 18\%; and sexual harassment $12 \%[4,5]$. The prevalence of violence in the workplace against nurses in China results that out of 588 nurses surveyed, $78 \%$ of nurses reported violent physical experiences and of these $93.5 \%$-from patients and $82 \%$ from their relatives.

\section{The Purpose of the Study}

To assess the current level of violence in the Regional Hospital of Vlora, as well as the knowledge that nurses have about their work, healthand safety [6].

\section{Specific Objectives}

- To assess the number of nurses who have suffered the consequences of psychological and physical violence in the workplace, respectively the nurses of the emergency department and surgery.

- Identify the causes of these violent episodes.

- Evaluate the degree of concern of information staff regarding this phenomenon.

- Identify the information of the nursing staff regarding the procedures to be followed to report the violence.

- Assess the needs of nurses to be part of various trainings related to protection against aggression and assess their effectiveness.

- Evaluate nurses' reactions to such cases of violence.

- Evaluate whether cases of violence have increased or decreased

\section{Methodology}

This is a descriptive analytical study conducted in Vlora Regional Hospital in the period November 2018December 2019. Data collection is using a self-administered questionnaire was completed by the two departments nurses, nurse of surgery department and urgency.

\section{Results}

Noted that in the emergency ward nurses are more likely to be part of violent physical acts. Both pavilions have a high rate of verbal violence in the nursing work. Verbal violence is higher than physical violence. Nurses in both pavilions claim to be informed that procedures exist to denounce violence

In the emergency department, most nurses were not physically abused $67 \%$, while a small proportion of them were raped $33 \%$ (Figure 1). In the surgery ward, only a small proportion of nurses claim that they have been physically abused $12 \%$, while the rest have not been physically abused $88 \%$. 

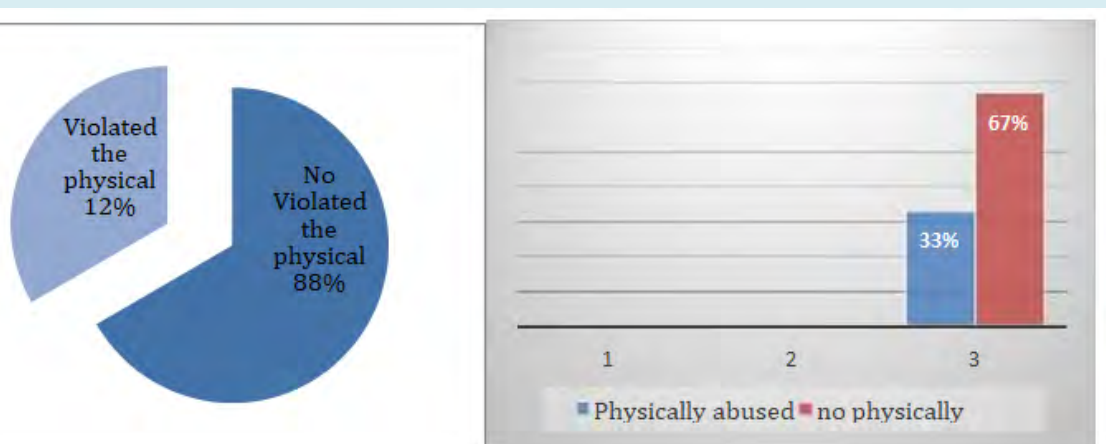

Figure 1: Distribution according to verbal violence exercised on nurses

Most emergency nurses' report being verbally abused $75 \%$, while the smallest part denies this 25\% (Figure 2).
Most nurses in surgery report being verbally abused, while the smallest part denies this.

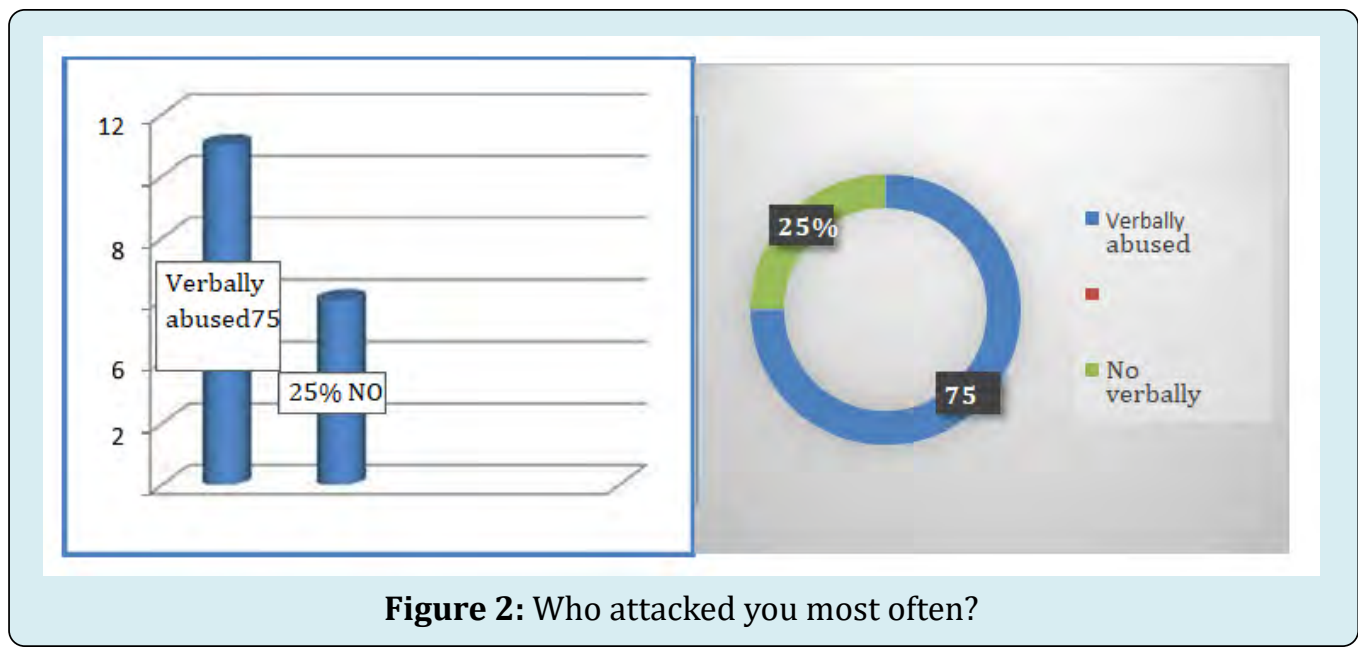

In the emergency department, nurses claim that in most cases they have been raped by the parents of the patients, another not insignificant part by relatives and a few by others and patients (Figure 3). In the surgery ward, nurses claim that in most cases they have been raped by the parents of the patients, another not insignificant part by the relatives and less by the others by the patients.

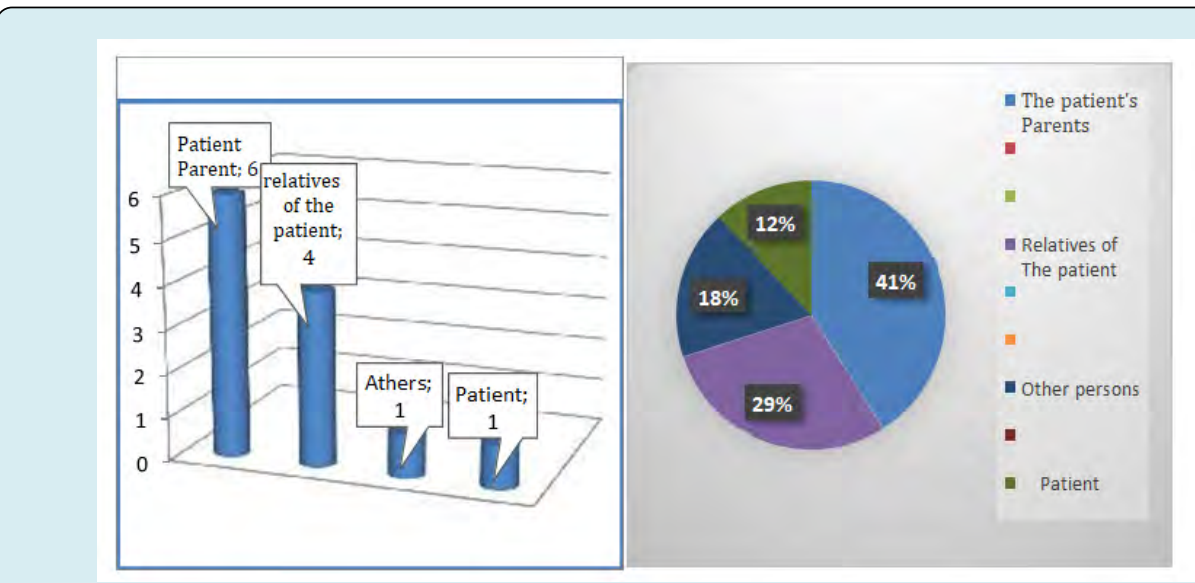

Figure 3: How did you respond to the aggression? 
In the emergency department, nurses in most cases have tried to protect themselves physically and very few have sought help from colleagues. In the surgical ward most of the nurses have sought help from colleagues and very few have tried to defend themselves physically (Figure 4).
In the emergency department, nurses claim that cases of violence have increased in this ward 100\%. In the surgery department, most nurses claim that cases of domestic violence have increased by $71 \%$ and very few deny that they have decreased by $29 \%$.

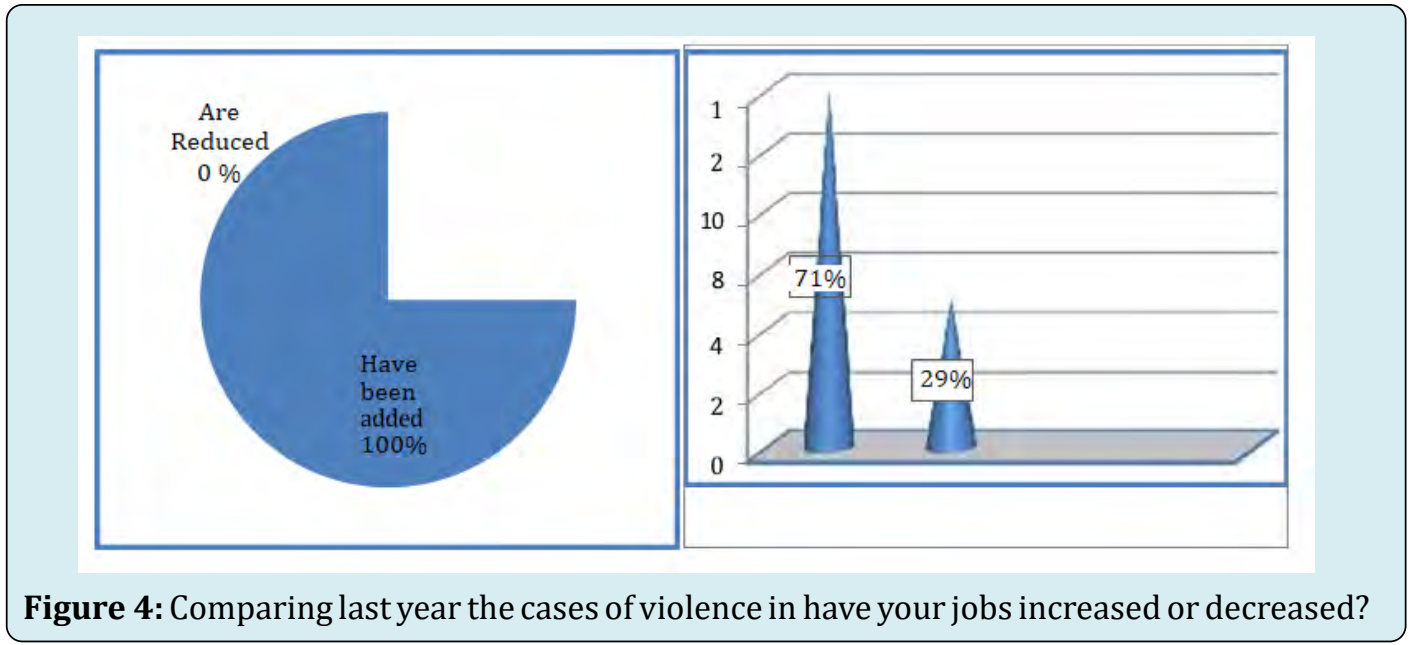

\section{Discussion}

$>$ It is noted that in the emergency department nurses are more predisposed to be part of violent physical acts due to the reasonable fact that it is the first ward to deal with patients and their families and logically the most endangered.

$>$ They claim that both wards have a high rate of verbal violence during the work of nurses. Verbal violence compared to physical violence is in a higher percentage in both wards studied.

$>$ Nurses assert their uncertainty about possible future improvements.

$>$ We understand that this phenomenon in both pavilions is caused by those who are closer to the patients, their family members and relatives. This is due to the fact that they are the ones who always insist on explanations and information from the nurses about the patient and his condition.

$>$ Emergency nurses are many times more concerned as they are the first to face each case.

$>$ Most nurses in both wards claim to be aware of the fact that there are procedures to report violence.

\section{Conclusions}

- Most nurses claim that they feel the need to participate in various trainings to protect themselves from violence and aggressors.
- Emergency nurses in most cases have been forced to physically defend themselves against aggression and very few of them have sought help from colleagues.

- While many of the surgical nurses have liked to seek help from colleagues and not to be physically protected.

\section{References}

1. European Agency for Occupational Safety and Health. Risk analysis, the key to healthy and safe work environments. Why should a risk analysis be performed?

2. Hernández, Gil F (2011) Treatise on Occupational Medicine. Elsevier Masson. Kindle Edition.

3. (2010) Public Health, Gentiana Qirjako, Genc Burazeri, Enver Roshi, Vitori Hasani.

4. (2012) Questionnaire on Occupational Health and Occupational Risks.

5. (2009) Carolina Gisel Rodriguez Bravo, Exposure to occupational hazards of emergency nursing professionals, intensive care unit, surgery rooms of the San Ignacio university hospital in the city of Bogota, during the period.

6. Prevention and Protection Service, Main Risks in the Hospital Environment. 